Case Report

\title{
Solitary Plasmacytoma in the Mandible Resembling an Odontogenic Cyst/Tumor
}

\author{
Fatemeh Rezaei, ${ }^{1}$ Hesamedin Nazari, ${ }^{2}$ and Babak Izadi $^{3}$ \\ ${ }^{1}$ Department of Oral Medicine, School of Dentistry, Kermanshah University of Medical Sciences, Kermanshah, Iran \\ ${ }^{2}$ Department of Oral and Maxillofacial Surgery, School of Medicine, Kermanshah University of Medical Sciences, \\ Kermanshah, Iran \\ ${ }^{3}$ Department of Pathology, School of Medicine, Kermanshah University of Medical Sciences, Kermanshah, Iran
}

Correspondence should be addressed to Hesamedin Nazari; hesamedin_nazari@yahoo.com

Received 21 August 2016; Revised 9 October 2016; Accepted 17 November 2016

Academic Editor: Leandro N. de Souza

Copyright ( $\odot 2016$ Fatemeh Rezaei et al. This is an open access article distributed under the Creative Commons Attribution License, which permits unrestricted use, distribution, and reproduction in any medium, provided the original work is properly cited.

A 46-year-old male patient referred to Department of Oral Medicine, with the primary chief complaint of a painless swelling in the right side of mandibular. A panoramic radiograph revealed a well-defined, multilocular radiolucent bony lesion with thin and straight septa in the right side of mandible extending from distal of canine to mesial of third molar. Histological examination showed a solid proliferation of atypical plasmacytoid cells, which was indicative of plasmacytoma. A systemic workup for the final diagnosis was performed to rule out multiple myeloma.

\section{Introduction}

The plasmacytoma is a neoplastic and monoclonal proliferation of plasma cells that usually arises within bones $[1,2]$. Most of the lesions present centrally within a single bone, and it occurs most frequently in the spine, vertebrae, femur, and pelvis $[3,4]$. Infrequently, it is seen in soft tissue, in which case, the term extramedullary plasmacytoma is used. The upper respiratory tract, especially the nasal cavity, oropharynx, nasopharynx, and sinuses, is frequently involved. It has a longer survival rate $[5,6]$. However, the extramedullary plasmacytoma can convert to plasmacytoma of bone and myeloma, both of which are associated with a poorer prognosis $[7,8]$.

The male to female ratio of solitary plasmacytoma is approximately $2: 1$, with an average age of 55 years $[9,10]$. The localization of solitary plasmacytoma of bone in head and neck is very rare and usually occurs in the sinonasal tract [11]. Approximately $12 \%$ to $15 \%$ of solitary plasmacytomas of the bone occur in the jaw and they are commonly involved in the posterior body of the mandible that can extend to angle and ramus [10].

\section{Case Presentation}

A 46-year-old male patient presented to the Department of Oral Medicine, Kermanshah University of Medical Sciences in 2015 with the primary chief complaint of a painless swelling in the right side of mandibular bone that he had first noticed 2 months before (Figure 1). He had medical history of epilepsy and seizures so he has consumed phenytoin and lamotrigine for about 13 years. He did not use tobacco, alcohol, or other intravenous drugs. His general health was good without fatigue, fever, or weight loss. Neurologic examination of cranial nerves V and VII was normal without visible skin changes or drainage. He had no complaint of paresthesia or anesthesia. Maximum opening of the mouth was $4 \mathrm{~cm}$, without deviation or clicking on the temporomandibular joint. Intraorally, the involved area had firm consistency without tenderness and was covered by normal mucosa (Figure 2).

He had generalized periodontitis and bone loss. Second molars premolars were mobile (grade II) and oral hygiene was poor. The third molar of the right mandible was nonvital but the other teeth on the same side were vital. There was no 


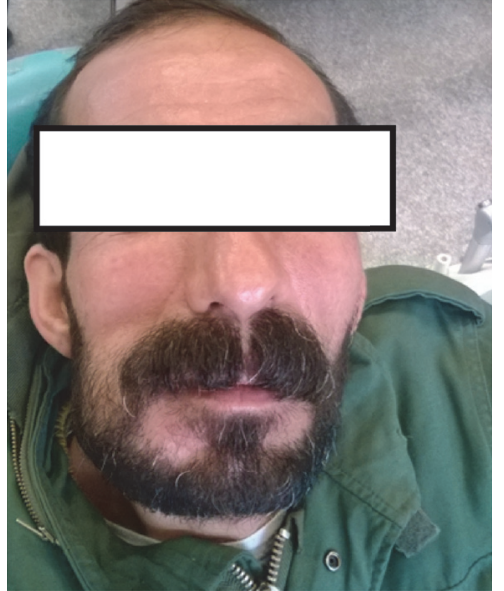

FIGURE 1: Swelling in the right side of mandibular bone.

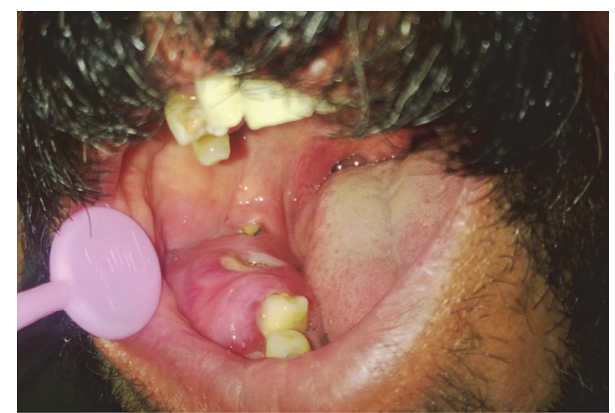

FIGURE 2: Clinical appearance of the expansion in the right side of mandible.

evidence of palpable submandibular, submental, or cervical lymphadenopathy.

A panoramic radiograph revealed a well-defined, multilocular radiolucent bony lesion with thin and straight septa in the right side of mandible extending from distal of canine to mesial of third molar. Resorption of the roots of the adjacent mandibular teeth did not occur (Figure 3).

Magnetic resonance imaging (MRI) was ordered to reveal the invasion and destruction of the lesion to the soft tissues. It revealed an expansile destructive lesion measuring about $4.4 * 6.3 \mathrm{~mm}$ is noted in right side of mandibular bone with extension to right side hypoglossus and mylohyoid muscles as well as outer subcutaneous fat and skin and right buccinators and master spaces.

2.1. Differential Diagnosis. An expansile multilocular radiolucent lesion in a middle-aged adult brings to mind a number of lesions that should be included in a differential diagnosis. The most common lesions based on the clinical manifestation and radiographic feature included odontogenic myxoma, ameloblastoma, and odontogenic keratocyst.

Odontogenic myxoma is an uncommon benign mesenchymal odontogenic tumor arising from the dental papilla, follicle, or the periodontal ligament [12]. It commonly involves the mandibular premolar and molar regions. It is most frequently seen in patients in the second to the third decades

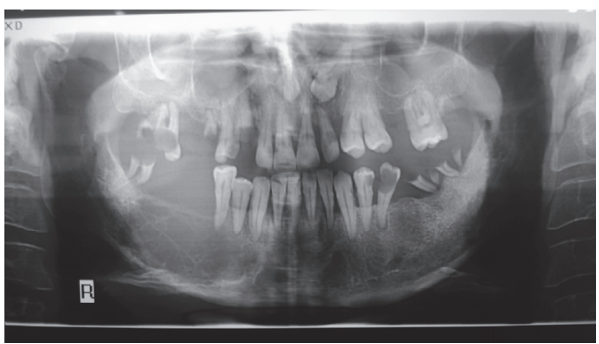

FIGURE 3: Panoramic radiograph demonstrating a large multilocular radiolucent lesion of the right mandible.

of life [13]. Odontogenic myxoma often grows without symptoms, most commonly presenting as a painless swelling [14]. Radiographically, its appearance ranges from unilocular to multilocular radiolucency with variable trabecular pattern giving rise to soap bubble, tennis racket, or honey comb appearance. Ideally, the septa that cause the multilocular feature are thin and straight, producing a tennis racket or stepladder pattern $[15,16]$. Locating several straight septa in panoramic feature propelled us to this tumor as a first diagnosis.

Ameloblastoma is one of the most frequent odontogenic tumors [17]. It is most commonly seen in adults in the third to fourth decade but may be found in patients over a wide age range $[18,19]$. Ameloblastoma most often presents as a hard painless intraoral swelling or as an incidental finding on routine dental imaging [20]. The radiographic features of conventional ameloblastoma are classified as unilocular or multilocular radiolucencies with well-defined borders [21].

The keratocystic odontogenic tumor (KOT) occurs in the 2nd and 3rd decade in the posterior body or in the ascending ramus of the mandible $[22,23]$. The radiographic appearance of KOT may range from a small unilocular radiolucency to a large multilocular radiolucency. Multiple KOTs are associated with Nevoid basal cell carcinoma syndrome [24].

\section{Diagnosis}

Aspiration of lesion was nonproductive, so excluding the possibility of vascular and cystic lesions.

An incisional biopsy of the bony lesion was performed under local anesthesia without significant bleeding.

Histological examination on hematoxylin and eosin (H\&E) staining showed a solid proliferation of atypical plasmacytoid cells with eccentric nuclei and basophilic cytoplasm, which was indicative of plasmacytoma (Figure 4).

In Complete Blood Count test (CBC and Diff test), white blood cell (WBC: 3600 cells $/ \mathrm{mL}$ ), red blood cell (RBC: $3.9 *$ $10^{6}$ cells $/ \mathrm{mL}$ ), hemoglobin ( $\mathrm{Hb}: 12.9 \mathrm{~g} / \mathrm{dL}$ ), and hematocrit (HCT: 36.6\%) were low but Mean Corpuscular Volume (MCV: $92.9 \mathrm{fL}$ ) and platelet $(171000 / \mathrm{mL})$ were in the normal range. In biochemistry test, urea $(37 \mathrm{mg} / \mathrm{dL})$ and creatinine $(1 \mathrm{mg} / \mathrm{dL})$ were normal and hypercalcaemia was not found so renal insufficiency was ruled out. Serum immunoelectrophoresis showed an increase in M-protein [immunoglobulin (IgG) $\kappa$ type] and also a decrease in albumin of plasma and albumin/globulin ratio was lower than normal. 


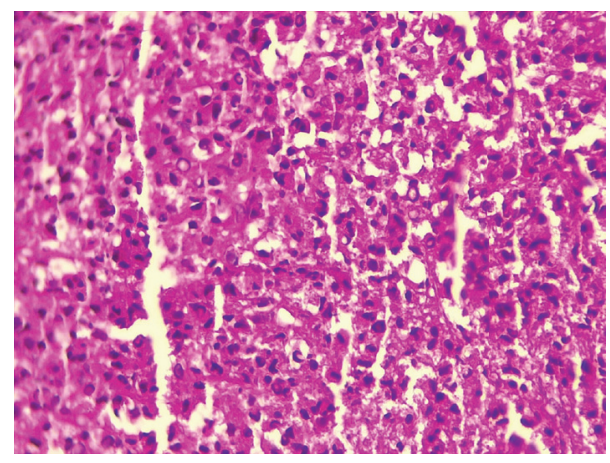

Figure 4: Diffuse infiltration of neoplastic large plasmablastic cells with pleomorphism and nuclei with one or several nucleoli (hematoxylin and eosin, original magnification $\times 40$ ).

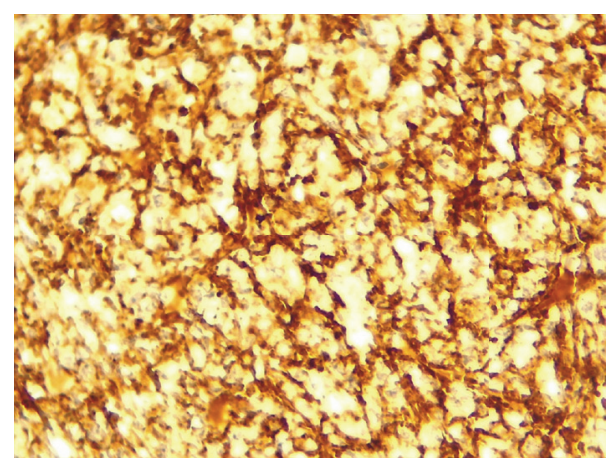

FIGURE 5: Immunohistochemical staining showing immunopositivity for CD138 $(\times 40)$.

A systemic workup for the final diagnosis was performed to rule out multiple myeloma. Radiographic survey including posteroanterior and lateral skull views was performed and showed no additional osteolytic lesion.

In immunohistochemical painting, CD138, vimentin, Ki67, and EMA were positive (Figures 5-8). But the immunohistochemical painting was negative for LCA, CK, CD3, CD20, CD1, NSE.

The patient was referred to haematooncologist. Bone marrow aspiration and trephine biopsy revealed hypercellular marrow with $6 \%$ plasma cell.

\section{Discussion}

Oral manifestations of solitary plasmacytoma of jaw include localized pain in the jaws and teeth, paresthesia, swelling, soft tissue masses, mobility and migration of teeth, hemorrhage, and pathological fracture. Fatigue and fever are the most common systemic symptoms $[25,26]$. Our patient just had expansion in posterior mandible and mobility and migration of his teeth were probably due to aggressive periodontitis. He did not report history of pain or paresthesia in the jaws and teeth. Asymptomatic solitary bone plasmacytoma of the jaw is very rare but such a clinical form without pain has been described previously [27].

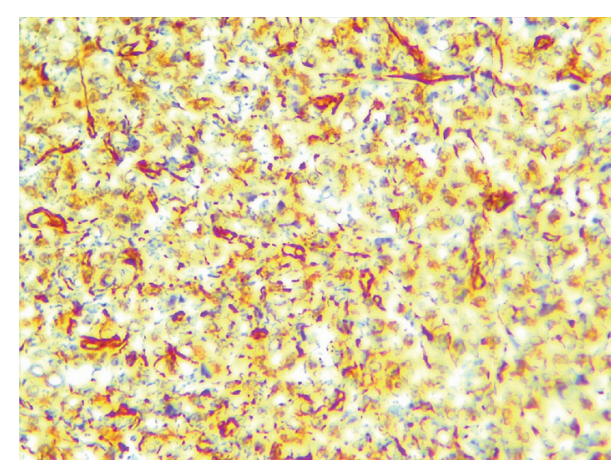

FIgURE 6: Immunohistochemical staining showing immunopositivity for vimentin $(\times 40)$.

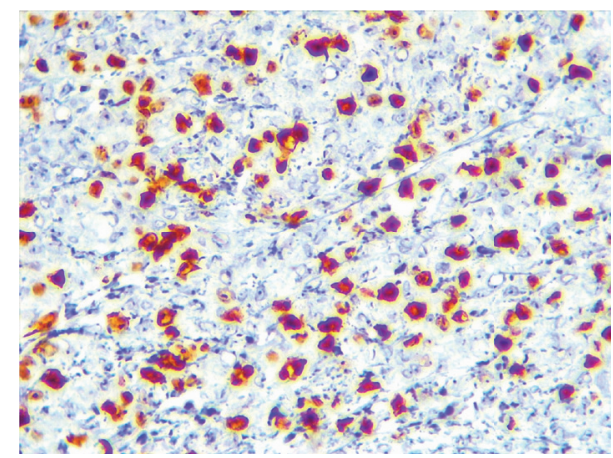

FIGURE 7: Immunohistochemical staining showing immunopositivity for Ki67 (×40).

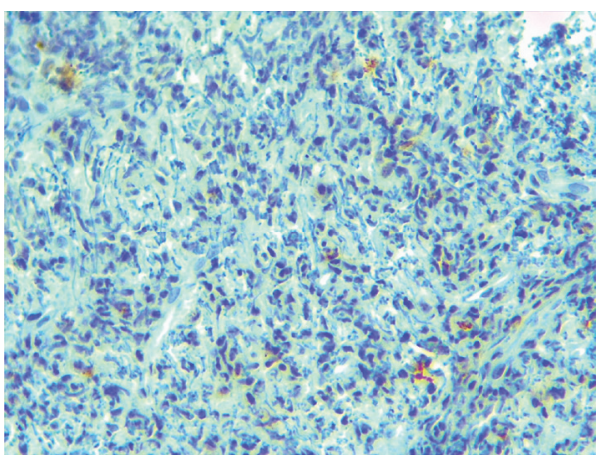

FIGURE 8: Immunohistochemical staining showing immunopositivity for EMA $(\times 40)$.

Solitary plasmacytoma of the mandible also has various radiographic findings: from well-defined, unilocular radiolucency or "punched-out" appearance similar to multiple myeloma (MM) to ill-defined destructive radiolucencies with ragged borders but without periosteal reaction [28-30]. The radiographic feature of the present case was well-defined, multilocular radiolucency with several straight septa that resembled odontogenic myxoma.

Diagnosis is based on the presence of malignant proliferation of plasma cells in the biopsy. 
Histological features of solitary plasmacytoma are identical to MM, Sheets, or clusters of atypical monoclonal plasma cells with various types of differentiation $[28,29]$.

Bone marrow biopsies are performed to ensure the disease is localized. In solitary and extramedullary plasmacytoma, there will not be an increase of monoclonal plasma cells in bone marrow $[28,30]$. Bone marrow aspiration in our patient revealed $6 \%$ plasma cell.

A typical antibody is composed of two immunoglobulin (Ig) heavy chains and two Ig light chains. A monoclonal protein (M-protein) is an abnormal immunoglobulin (IgG) light chain that is produced in excess by an abnormal clonal proliferation of plasma cells $[31,32]$. Diagnosis of this present case was confirmed as solitary plasmacytoma, because laboratory examination showed the presence of M-protein [immunoglobulin (IgG) $\kappa$ type] on serum electrophoresis. $25 \%$ to $50 \%$ of patients show a monoclonal gammopathy on evaluation by serum protein immunoelectrophoresis, although the amount of abnormal protein is much less than seen with MM reflecting the lower tumor burden $[31,32]$.

In immunohistochemical painting, CD138, vimentin, and EMA were positive. Also Ki67 was positive in $70 \%$ of tumoral cells. The results of the present case are in accordance with some studies who reported that these atypical cells react positively for CD138 and k-light chain, whereas staining with CD20, CD1, and NSE is essentially negative which ruled out epithelial, muscle, neural, histiocytic, and salivary gland origin of the tumor cells $[6,31]$.

An early diagnosis of solitary plasmacytoma of bone is essential to patient survival rate. It may represent the first manifestation of $\mathrm{MM}$ and conversion to MM occurring in about $70 \%$ of cases at an average of 20.7 months after initial diagnosis $[28,29]$. So a systemic workup should be obtained early after diagnosis of the lesion to rule out the existence of this systemic disease $[32,33]$.

The patient did not show typical complications of MM, such as bone pain, skeletal destruction with osteolytic lesions, pathological fractures, limited mobility, hypercalcaemia, renal failure, and end-organ/tissue damage [34, 35].

$\mathrm{CBC}$ and Diff test showed WBC, RBC, Hb, and HCT were lower than normal range; however, this patient has consumed phenytoin and lamotrigine for about 13 years so these drugs can cause dyscrasias [36].

Solitary plasmacytomas are highly radiosensitive lesions. Radiation therapy, radical extensive surgery, or a combination of both is recommended as primary treatment. Radical radiotherapy comprising of 40-50 Gy has shown $80 \%$ of local disease control [9]. So the treatment used most commonly for both types of plasmacytoma is radiation therapy. Although chemotherapy is generally not used, treatment by local radiation and chemotherapy may delay converting it to multiple myeloma [37].

Surgery is rarely necessary but may be required in situations where plasmacytoma involvement of the bone causes skeletal instability and high risk of fracture. In these cases, radiation therapy may be delayed until after surgery. All patients with plasmacytomas require follow-up for at least the first five years after treatment has been completed. The course of solitary plasmacytoma of bone is relatively benign and the
5 -year survival rate of it is $60 \%$; however, it falls to $5.7 \%$ when progression to multiple lesions occurs [30].

The patient in the current case demonstrated partial response to radiation ( $40 \mathrm{~Gy}$ in 20 fractions) and chemotherapy (cyclophosphamide, hydroxydaunorubicin, and prednisone).

The disease remains stable and nonprogressive at this time. He is scheduled for at least 5-year follow-up appointments.

\section{Conclusion}

In this paper, we reported a male patient with a large destructive lesion in the posterior of mandible. It presented as an expansile multilocular radiolucent lesion, clinically and radiographically resembling an odontogenic cyst/tumor but it was solitary plasmacytoma.

\section{Consent}

Written informed consent was obtained from the patient for publication and presenting of this case and any accompanying images.

\section{Competing Interests}

The authors declare that there is no conflict of interests regarding the publication of this article.

\section{References}

[1] S. Matsumura, M. Kishino, T. Ishida, and S. Furukawa, "Radiographic findings for solitary plasmacytoma of the bone in the anterior wall of the maxillary sinus: a case report," Oral surgery, oral medicine, oral pathology, oral radiology, and endodontics, vol. 89, no. 5, pp. 651-657, 2000.

[2] J. J. Pisano, R. Coupland, S.-Y. Chen, and A. S. Miller, "Plasmacytoma of the oral cavity and jaws: a clinicopathologic study of 13 cases," Oral Surgery, Oral Medicine, Oral Pathology, Oral Radiology, and Endodontology, vol. 83, no. 2, pp. 265-271, 1997.

[3] N. Sharma, A. Singh, A. Pandey, and V. Verma, "Solitary plasmacytoma of the mandible: a rare case report," National Journal of Maxillofacial Surgery, vol. 6, no. 1, pp. 76-79, 2015.

[4] V. Sychra, D. Eßer, H. Kosmehl, and M. Herold, "Unusual manifestation of a multiple myeloma in the hyoid bone," Dentomaxillofacial Radiology, vol. 42, no. 3, Article ID 27101530, 2013.

[5] S. Kalayoglu-Besisik, I. Yonal, F. Hindilerden, M. Agan, and D. Sargin, "Plasmacytoma of the nasolacrimal duct simulating dacryocystitis: an uncommon presentation for extramedullary relapse of multiple myeloma," Case Reports in Oncology, vol. 5, no. 1, pp. 119-124, 2012.

[6] L. M. Gonzalez-Perez and J. J. Borrero-Martin, "An elderly man with a gingival mass that spontaneously regressed," Oral Surgery, Oral Medicine, Oral Pathology and Oral Radiology, vol. 121, no. 4, pp. 348-352, 2016.

[7] M. Ozsahin, R. W. Tsang, P. Poortmans et al., "Outcomes and patterns of failure in solitary plasmacytoma: a multicenter rare cancer network study of 258 patients," International Journal of Radiation Oncology, Biology, Physics, vol. 64, no. 1, pp. 210-217, 2006. 
[8] C. Alexiou, R. J. Kau, H. Dietzfelbinger et al., "Extramedullary plasmacytoma: tumor occurrence and therapeutic concepts," Cancer, vol. 85, pp. 2305-2314, 2000.

[9] B. Rodríguez-Caballero, S. Sanchez-Santolino, B. García-Montesinos-Perea, M.-F. Garcia-Reija, J. Gómez-Román, and R. SaizBustillo, "Mandibular solitary plasmocytoma of the jaw: a case report," Medicina Oral, Patologia Oral y Cirugia Bucal, vol. 16, no. 5, pp. e647-e650, 2011.

[10] L. N. Souza, L. C. Farias, L. A. N. Santos, R. A. Mesquita, H. Martelli Jr., and A. M. B. De-Paula, "Asymptomatic expansile lesion of the posterior mandible," Oral Surgery, Oral Medicine, Oral Pathology, Oral Radiology, and Endodontology, vol. 103, no. 1, pp. 4-7, 2007.

[11] G. Bachar, D. Goldstein, D. Brown et al., "Solitary extramedullary plasmacytoma of the head and neck-Long-term outcome analysis of 68 cases," Head and Neck, vol. 30, no. 8, pp. 1012-1019, 2008.

[12] S. Reddy, A. Naag, and B. Kashyap, "Odontogenic myxoma: report of two cases," National Journal of Maxillofacial Surgery, vol. 1, no. 2, pp. 183-186, 2010.

[13] S. F. Khan, P. Agrawal, and J. Sur, "A rare case report of myxoid fibroma of maxilla," Quantitative Imaging in Medicine and Surgery, vol. 5, no. 5, pp. 778-782, 2015.

[14] H. Rashid and A. Bashir, "Surgical and prosthetic management of maxillary odontogenic myxoma," European Journal of Dentistry, vol. 9, no. 2, pp. 277-283, 2015.

[15] R. K. Manne, V. S. Kumar, P. V. Sarath, L. Anumula, S. Mundlapudi, and R. Tanikonda, "Odontogenic myxoma of the mandible," Case Reports in Dentistry, vol. 2012, Article ID 214704, 4 pages, 2012.

[16] R. Subramaiam, S. Narashiman, M. Narasimhan, V. Giri, and S. Kumar, "Odontogenic myxoma of the maxilla: a rare case report," Journal of Clinical and Diagnostic Research, vol. 9, no. 5, pp. ZD29-ZD31, 2015.

[17] E. N. M. Simon, M. A. W. Merkx, E. Vuhahula, D. Ngassapa, and P. J. W. Stoelinga, "A 4-year prospective study on epidemiology and clinicopathological presentation of odontogenic tumors in Tanzania," Oral Surgery, Oral Medicine, Oral Pathology, Oral Radiology and Endodontology, vol. 99, no. 5, pp. 598-602, 2005.

[18] R. R. Throndson and S. B. Sexton, "A mandibular central lesion with unusually rapid growth," Oral Surgery, Oral Medicine, Oral Pathology, Oral Radiology and Endodontology, vol. 98, no. 1, pp. 4-9, 2004.

[19] M. R. Darling and T. D. Daley, "Radiolucent lesion of the anterior mandible," Oral Surgery, Oral Medicine, Oral Pathology, Oral Radiology and Endodontology, vol. 99, no. 5, pp. 529-531, 2005.

[20] M. P. Chae, N. R. Smoll, D. J. Hunter-Smith, and W. M. Rozen, "Establishing the natural history and growth rate of ameloblastoma with implications for management: systematic review and meta-analysis," PLoS ONE, vol. 10, no. 2, Article ID e0117241, 2015.

[21] J. Mahadesh, D. K. Rayapati, P. M. Maligi, and P. Ramachandra, "Unicystic ameloblastoma with diverse mural proliferation-a hybrid lesion," Imaging Science in Dentistry, vol. 41, no. 1, pp. 29-33, 2011.

[22] J. De Lange and H. P. Van Den Akker, "Clinical and radiological features of central giant-cell lesions of the jaw," Oral Surgery, Oral Medicine, Oral Pathology, Oral Radiology and Endodontology, vol. 99, no. 4, pp. 464-470, 2005.
[23] L. Avril, T. Lombardi, A. Ailianou et al., "Radiolucent lesions of the mandible: a pattern-based approach to diagnosis," Insights into Imaging, vol. 5, no. 1, pp. 85-101, 2014.

[24] H. Myoung, S.-P. Hong, S.-D. Hong et al., "Odontogenic keratocyst: review of 256 cases for recurrence and clinicopathologic parameters," Oral Surgery, Oral Medicine, Oral Pathology, Oral Radiology, and Endodontics, vol. 91, no. 3, pp. 328-333, 2001.

[25] C. E. Poggio, "Plasmacytoma of the mandible associated with a dental implant failure: a clinical report," Clinical Oral Implants Research, vol. 18, no. 4, pp. 540-543, 2007.

[26] R. Ozdemir, O. Kayiran, M. Oruc, O. Karaaslan, U. Koçer, and D. Ogun, "Plasmacytoma of the hard palate," Journal of Craniofacial Surgery, vol. 16, no. 1, pp. 164-169, 2005.

[27] E. M. Canger, P. Celenk, A. Alkan, and O. Günhan, "Mandibular involvement of solitary plasmocytoma: a case report," Medicina Oral, Patología Oral y Cirugía Bucal, vol. 12, no. 1, pp. E7-E9, 2007.

[28] J. J. Pisano, R. Coupland, S.-Y. Chen, and A. S. Miller, "Plasmacytoma of the oral cavity and jaws: a clinicopathologic study of 13 cases," Oral Surgery, Oral Medicine, Oral Pathology, Oral Radiology, and Endodontics, vol. 83, no. 2, pp. 265-271, 1997.

[29] S. Y. An, C. H. An, K. S. Choi, and M. S. Heo, "Multiple myeloma presenting as plasmacytoma of the jaws showing prominent bone formation during chemotherapy," Dentomaxillofacial Radiology, vol. 42, no. 4, Article ID 20110143, 2013.

[30] J. A. Jeong, G. E. Seo, J. H. Song, and S. J. Park, "Solitary plasma cell myeloma on anterior maxilla: a case report," Journal of Korean Association of Maxillofacial Plastic and Reconstructive Surgeons, vol. 32, pp. 77-80, 2010.

[31] R. W. McKenna, R. A. Kyle, W. M. Kuehl, T. M. Grogan, N. L. Harris, and R. W. Coupland, "Plasma cell neoplasms," in WHO Classification of Tumours of Haematopoietic and Lymphoid Tissues, S. H. Swerdlow, E. Campo, N. L. Harris et al., Eds., pp. 200-213, IARC, Lyon, France, 2008.

[32] H. Kaur, S. Parhar, S. Kaura et al., "A large painless swelling of the posterior mandible," Oral Surgery, Oral Medicine, Oral Pathology and Oral Radiology, vol. 115, no. 2, pp. 152-156, 2013.

[33] J. H. Yoon, J. I. Yook, H. J. Kim, I. H. Cha, W. I. Yang, and J. Kim, "Solitary plasmacytoma of the mandible in a renal transplant recipient," International Journal of Oral and Maxillofacial Surgery, vol. 32, no. 6, pp. 664-666, 2003.

[34] E. Coşkun, Ö. Başlarlı, A. Aktaş, H. Tüz, and Ö. Günhan, "Multiple myeloma presenting as paresthesia," Oral Surgery, Oral Medicine, Oral Pathology and Oral Radiology, vol. 119, no. 3, p. e150, 2015.

[35] Á. M. Miranda, S. M. Amaral, F. R. Pires, J. de Noronha Santos Netto, C. C. Queiroz, and J. de Moraes Pereira, "Multiple myeloma: primary oral presentation of 3 aggressive cases," Oral Surgery, Oral Medicine, Oral Pathology and Oral Radiology, vol. 120, no. 2, article no. e22, 2015.

[36] S. C. Blackbum, A. D. Oliart, L. A. Garca Rodríguez, and S. Peréz Gutthann, "Antiepileptics and blood dyscrasias: a cohort study," Pharmacotherapy, vol. 18, no. 6, pp. 1277-1283, 1998.

[37] S. Marotta and P. Di Micco, "Solitary plasmacytoma of the jaw," Journal of Blood Medicine, vol. 1, pp. 33-36, 2010. 


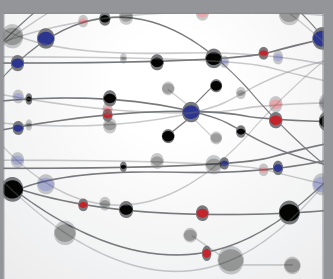

The Scientific World Journal
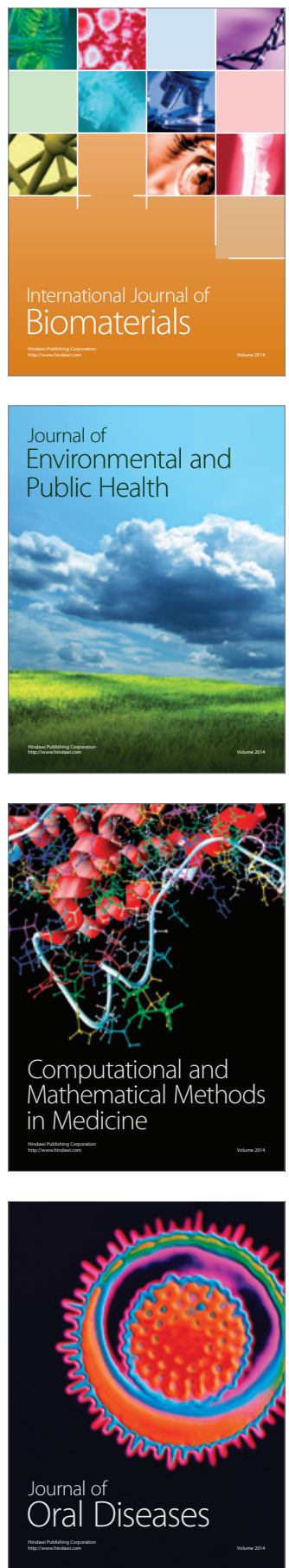
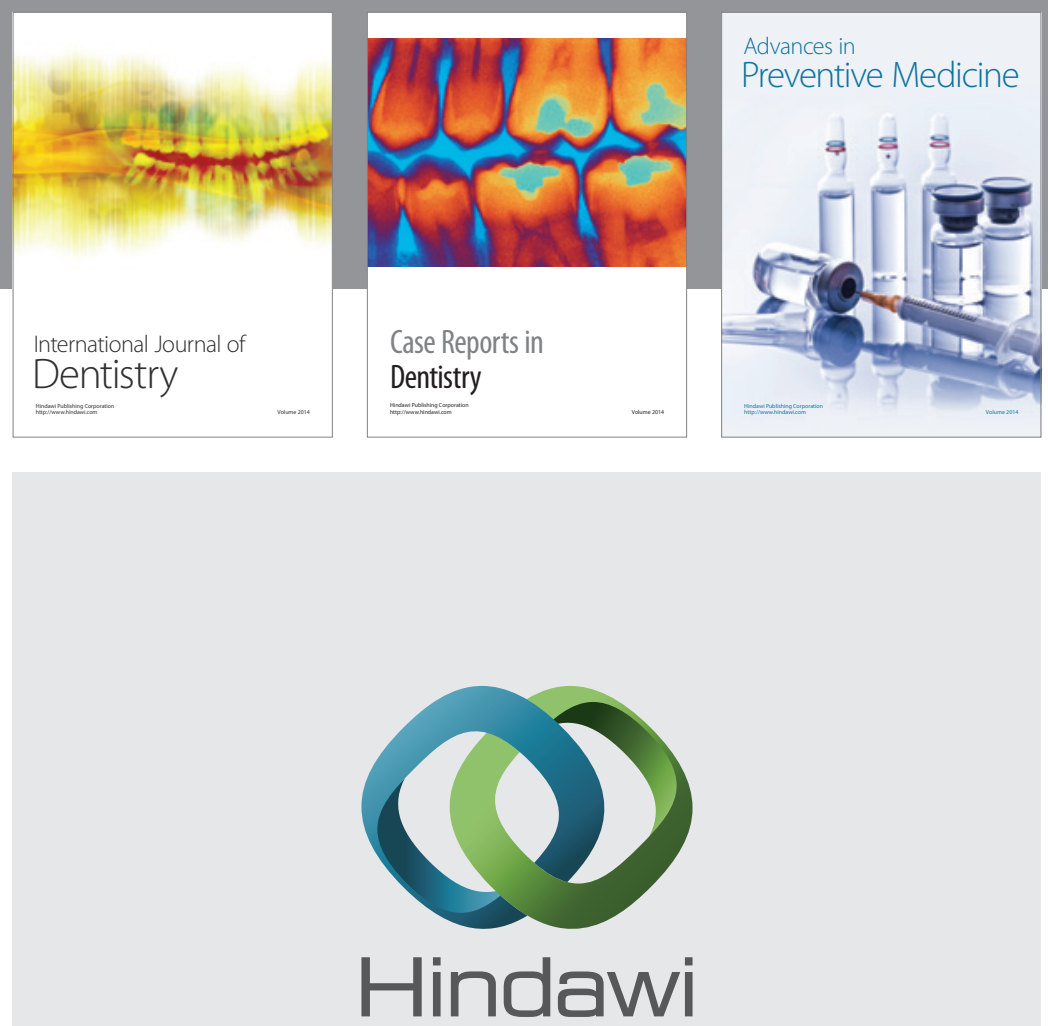

Submit your manuscripts at

http://www.hindawi.com
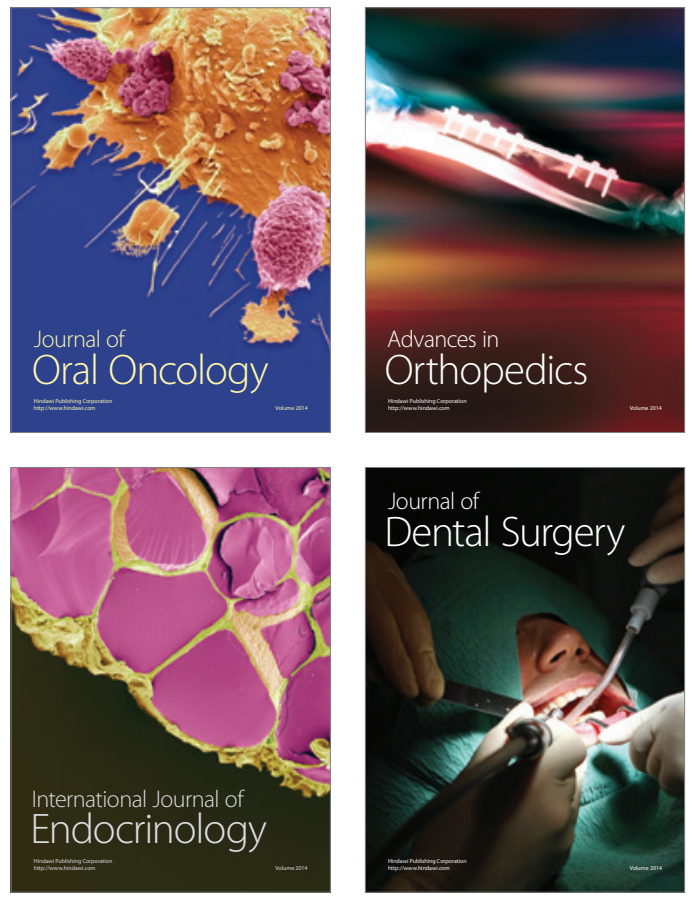
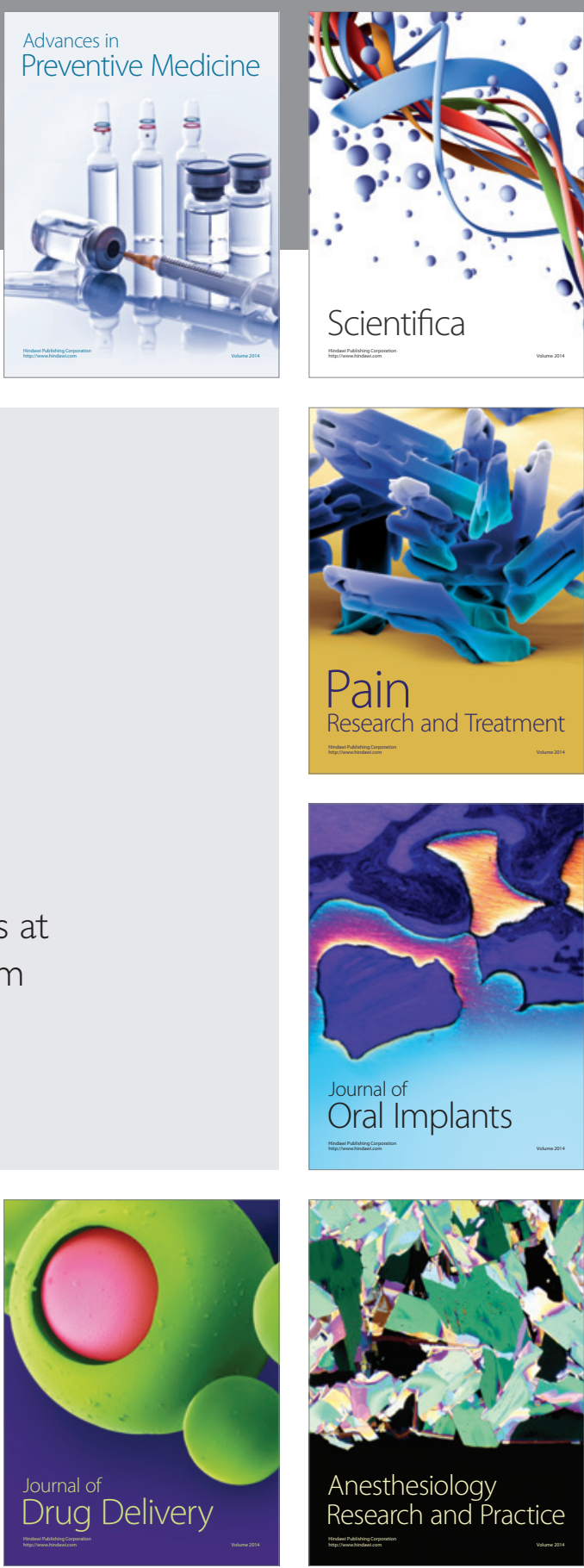

Scientifica
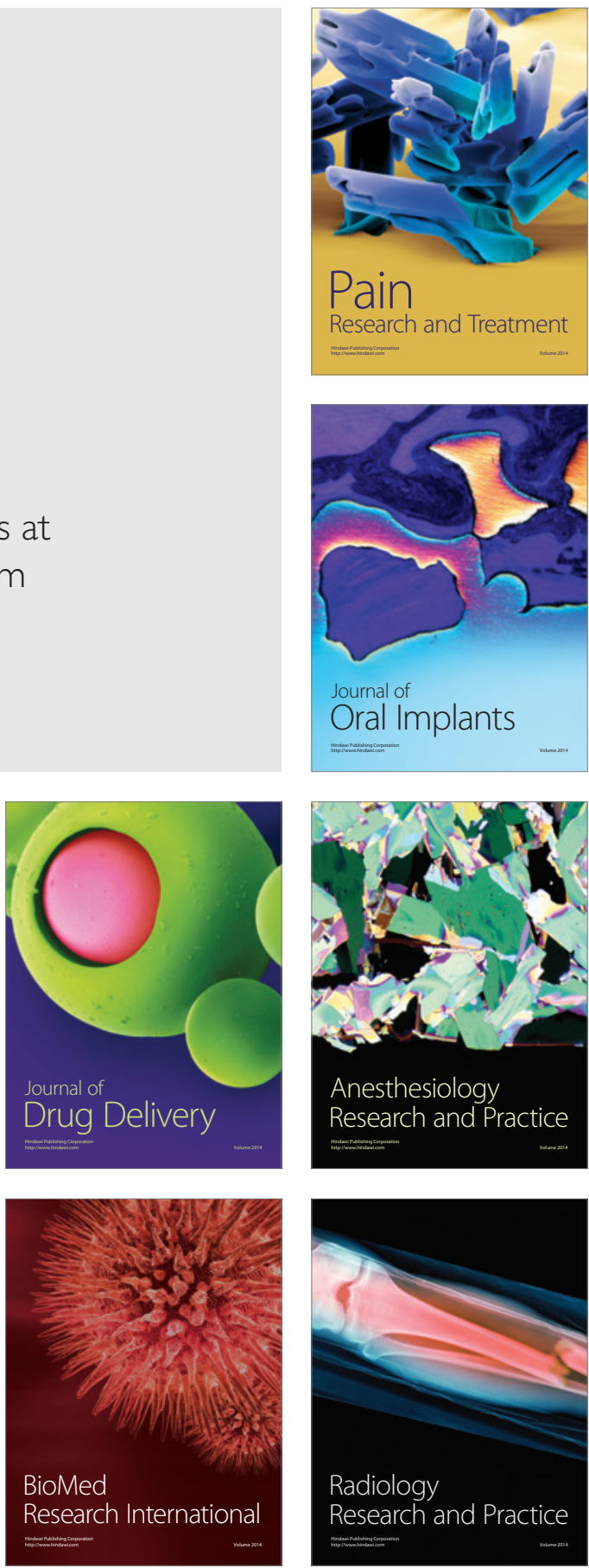